\title{
Livelihood resilience in the face of climate change
}

This final post peer-review version submitted to journal Nature Climate Change. Published as:

Tanner, T.M., Lewis, D., Wrathall, D., Bronen, R., Cradock-Henry, N., Huq, S., Lawless, C., Nawrotzki, R., Prasad, V., Rahman, M.A. and Alaniz, R. (2015) Livelihood resilience in the face of climate change, Nature Climate Change 5: 23-26.

\section{Abstract}

The resilience concept requires greater attention to human livelihoods if it is to address the limits to adaptation strategies and the development needs of the planet's poorest and most vulnerable people. Although the concept of resilience is increasingly informing research and policy, its transfer from ecological theory to social systems leads to weak engagement with normative, social and political dimensions of climate change adaptation. A livelihood perspective helps strengthen resilience thinking by placing greater emphasis on human needs and their agency, empowerment and human rights, and considering adaptive livelihood systems in the context of wider transformational changes.

\section{Navigating the resilience renaissance}

Resilience has become a popular research and policy concept within climate change adaptation and development contexts ${ }^{1}$. Emerging from a wide range of disciplines ${ }^{2}$, resilience in policy-making has often been based on the property of systems to bounce back to normality, drawing on engineering concepts ${ }^{3}$. This implies the return of the functions of an individual, household, community or ecosystem to previous conditions, with as little damage and disruption as possible following shocks and stresses. This stable-equilibrium view has been challenged by research on linked social-ecological systems (SES), which emphasizes non-linear change, the inevitability of uncertainty and surprise (which may destabilize attempts to manage the capacity of systems to cope with change), and inter-relationships and dynamism of multiple cross-scale systems ${ }^{4}$. Crucially, resilience is increasingly providing an integrative 'boundary concept' that brings together those interested in tackling a range of shocks and stresses, including food security, social protection, conflict and disasters ${ }^{5}$.

This perspective article argues that three key areas linked to livelihood approaches can help to overcome the challenges of employing resilience thinking in order to inform improved 
climate change adaptation research on the issue of highest normative priority - human livelihoods.

\section{Challenges of resilience for adaptation}

Applying the concept of resilience to climate change adaptation raises some complex challenges. Climate change is not exclusively an environmental problem that can be addressed purely in scientific, managerial or technical ways. Climate change is also crucially a conundrum of politics and justice, with unequal contributions to the problem globally, disproportionate impacts on future generations, marginalized groups and poorer citizens, whose poverty may itself be the result of historical inequities, and asymmetries in decision making power to determine appropriate responses ${ }^{6}$.

The concept of resilience requires strengthening in three main ways. First we need to recognize its contested nature. When considering resilience as an 'end', it cannot be assumed that there is consensus around the nature of 'desired states'. Resilience is contingent on social values regarding what we deem important and how we ought to allocate resources to foster it $^{7}$. People may be perpetually locked into resilient but undesirable states of poverty and marginality. Instead, we need to ask 'resilience of what type, and for whom?' and ask who decides, on the basis of what value systems ${ }^{8}{ }^{9}$ ?

Second, we need to understand how values and ideologies translate into activities and institutions that characterize the political economy of climate change resilience ${ }^{10}{ }^{11}$. For example, resilience studies concerned with ecosystem services for human well-being need to focus more on whose needs are being met, on the politics of ecosystem management and distribution of benefits ${ }^{12}$. This enables us to engage directly with power relations, differentiated access to resources, and issues of inequality that might otherwise be lost in resilience approaches ${ }^{13}$. In particular, there are trade-offs in which the resilience of some peoples' livelihoods may result in the increased vulnerability of others' (for example, through downstream impacts of flood protection measures ${ }^{14}$ ). These questions help to bring normative issues to the fore, and emphasize the distributional and political dimensions of the response options available to different actors ${ }^{15}$.

Third, though climate change impacts manifest through local ecosystems, the focus of resilience thinking on 'natural' systems may lose sight of the people inhabiting them and their differentiated vulnerability and capacities to adapt to change. Both disturbances and responses are determined by levels of on-the-ground social inequality, rights and unequal access to resources, poverty, poor infrastructure, lack of representation, and inadequate systems of social protection, planning, and risk management. The unevenness of these factors translates climatic fluctuations into disproportionate concentrations of suffering and loss ${ }^{16}$. 
Much work on resilience therefore pays insufficient attention to fundamental issues of human agency and empowerment, including world-view, risk perception, the diversity of cultural values, politics and power relations, as well as capacities for human (rather than environmental) transformation that lie at the heart of adaptation ${ }^{17}$. We argue that livelihood perspectives can usefully address some of these challenges. In doing so, we move resilience approaches beyond the predominantly scientific and technical discourses that are alien to the daily practices of ordinary people ${ }^{18}$.

\section{Livelihood resilience for research and practice}

In responding to recent calls for a social and political turn in resilience thinking 192021 22, we define livelihood resilience as the capacity of all people across generations to sustain and improve their livelihood opportunities and well-being despite environmental, economic, social and political disturbances. Such resilience is underpinned by human agency and empowerment, by individual and collective action, and by human rights, set within dynamic processes of social transformation. This approach takes the additional step of integrating livelihoods and resilience ${ }^{23} 24$ with a normative framing, centered on people as the central actors within adaptation policy and practice, underpinned by rights and justice, and engaged with wider development processes.

Climate change and associated stressors influence human development through their support or destabilization of the livelihood systems of the poorest and most vulnerable people.

Consequently, there is a human imperative to frame research and practice on climate change around livelihoods. A livelihood is understood to comprise 'the capabilities, assets (stores, resources, claims and access) and activities required for a means of living ${ }^{25}$. Within the field of development, the concept of livelihoods has drawn from diverse origins into a more coherent set of ideas during the past two decades. The extension of livelihoods research into policy and practice was accelerated by the sustainable livelihoods framework. This was developed for use by international agencies to guide programs for poverty alleviation by situating household livelihood assets within wider sets of ecosystems, cultural contexts and policies that promote or hinder access to these diverse resource inputs ${ }^{26} 27$. Crucially, a livelihood perspective places people at the center of the analysis, located within, rather than dominated by, ecosystems, technologies, political contexts, markets, and resource networks.

Livelihood resilience therefore highlights the role of human agency, and our individual and collective capacity to respond to stressors. People and their lives are too often reduced to homogenized vulnerable communities or countries, becoming merely 'resilient pixels ${ }^{\text {28 }}$. Even in discussions of agency, human responses to environmental change are too often expressed as generalized inputs within prescriptions for resilience ${ }^{29}{ }^{30}$. In contrast, a livelihood resilience approach emphasizes people's capacity for, and differences in, perceiving risk and taking anticipatory actions, either individually or collectively. 
Information and resource flows through social networks (as understood in theories of social capital) are vital inputs to resilience, providing informal insurance, and delivering accessible financial, physical and logistical support in the midst of environmental disturbances ${ }^{31}$. Modelling such agency and behavior remains a critical challenge ${ }^{32}$.

A livelihood resilience lens also incorporates a human rights perspective into resilience thinking. Human rights principles are based on the fundamental freedoms inherent in human dignity. These rights are translated into entitlements that transcend the sovereignty of nation state governments ${ }^{33}$. Articulating universal principles guaranteeing the right to food, housing, health and property - all critical to human dignity - and incorporating these into a resilience approach establishes a normative and legal basis for defining, measuring and promoting 'desirable states' in livelihood systems. A human rights framework also prioritizes the harm caused by climate-induced environmental change and creates a moral and legal obligation to respond, including through anticipatory adaptive measures.

By prioritizing the freedoms and entitlements explicitly outlined in human rights as a foundation for adaptation, livelihood resilience also emphasizes the fundamental obligation of governments to protect and support their citizens' development. Reframing resilience in rights terms places a duty on nation states to improve the living conditions of poor people living in vulnerable situations. Where nation states do not have the resources or capacities to protect the rights of its citizens, then a human rights perspective requires a focus on building the capacity of a nation state to meet its obligations to its citizens ${ }^{34}$. This includes the enactment of legislation to regulate and control private sector and other actors from committing human rights violations and also to define access to basic necessities, such as housing and healthcare.

Right-based approaches to development popularized in recent decades have used rights framings, with advocacy activities to secure wider popular participation in formal and informal decision making processes, fostering deepened democratic engagements with governmental processes, and focusing on empowerment of the most marginalised people and given greater attention to diversity and difference in relation to gender, ethnicity, culture and age $^{35}$. Such approaches have linked individual and community empowerment with advocacy for human rights protections.

The right to self-determination provides an opportunity for the qualities and dimensions of resilience to be informed or determined by individuals and communities themselves (see Box 1 for examples in practice). Linking livelihoods and self-determination in this way also highlights the importance of empowering people so that they can develop political influence and relationships with local government in order to access the resources they need to adapt to climate change impacts ${ }^{36}$. This cross-scale incorporation of human rights protections into the concept of livelihood resilience can thus challenge longstanding power structures and weak governance that reproduce vulnerability, rather than conceptualizing resilience as absolving states and the international community from duties around environmental impacts ${ }^{37} 38$. 


Box 1: Rights and resilience in action
The gono gobeshona (people’s research) approach of NGO Action Aid Bangladesh (AAB)
has emphasized local-level problem diagnosis and action based on articulating rights.
Following basic training, community level teams researched local climate change impacts,
developed adaptation options and articulated their experiences and needs to external
audiences. One agricultural community, close to a commercial shrimp cultivation area,
negotiated government agreement to close embankment sluice gates that were salinizing local
water quality, as well as trialing a new saline tolerant rice variety (BRRI Dhan 47 ) to
strengthen agricultural livelihoods ${ }^{40}$.
In Alaska, the Newtok Traditional Council, is using a livelihood resilience framework to
guide the relocation of their community. Newtok is a Yup’ik Eskimo community highly
dependent on subsistence hunting and fishing for food and a small cash economy. The
community has decided to relocate as the only means to protect them from climate-induced
environmental change. To improve the standard of living of community residents and
increase the community’s cash economy, the Council has designated funding to train
community members in construction skills so that they can build the infrastructure at their
relocation site and generate income ${ }^{41}$.

Finally, climate change is already contributing to physical transformations of planet earth, threatening habitability in semi-arid regions, coastal regions, islands and deltas. Such impacts are a pressing concern given the scale and speed of global environmental changes, the potential for anthropogenic climate change in excess of $4^{\circ} \mathrm{C}$, and their likely interactions to generate novel hazards ${ }^{42}$. A focus on livelihood resilience calls us to focus less on recovery from shocks and more on how coping and adaptation strategies are related to aspects of social transformation ${ }^{434} 45$. Mainstream views of resilience have tended to privilege the persistence of a system over its transformation, and the reassembly of the same societal conditions which contributed to the original disruption ${ }^{46}$. Integrating transformational perspectives means asking difficult questions of adaptation strategies that may interpret resilience as a move to low-risk, low return activities that may in turn close potential pathways to commercialization, diversification and poverty reduction.

Research into linked social-ecological systems (SES), which emphasises the inseparability of human and natural systems, has engaged deeply with thresholds and transformations, and has shown the linkages of biophysical parameters to human systems ${ }^{48}$. This has pushed systems thinking into the domains of human institutions, studying the effect of resource management 
regimes and resource politics, and their relationship to ecological transformations ${ }^{49}$. These extensions of resilience thinking are critical. A livelihood perspective pushes further to situate local thresholds as influencing and influenced by wider development transformations, such as processes of democratisation, globalization, social and political movements, urbanization, and diffusion of information and communications technology.

Focusing on these transformational aspects of resilience helps us to consider radically different livelihood strategies that may be necessary to respond to climate change and the significant trade-offs involved. Some forms of adaptation may impoverish people and build very powerful systems of negative resilience. In this way, adaptation, for example from traditional modes of agriculture to more precarious urban waged employment, is recast as a contested transformation. Adaptation of this kind can therefore be seen as a process of triage involving the things society values least, with some adaptive responses equated to the relinquishing of certain values, development goals and possibly even the acceptance of conditions of poverty. Instead, livelihood resilience, as we frame it here, prioritizes reformulations of livelihood systems that deliver the most vulnerable people through destabilizing global changes on their own terms, in ways that protect basic human dignity.

\section{Livelihood resilience for adaptation futures}

Livelihoods are increasingly caught between major global transitions in both climate and social systems. The impact of dangerous climate change falls disproportionately on the livelihood systems of the poorest citizens, undermining their capacity to build sustainable livelihoods and increasing their vulnerability. Understanding the resilience of livelihood systems of poor people in the context of wider transformational shifts - social and political as well as biophysical - must now be seen as a normative priority ${ }^{50}$. Even incremental improvements in livelihoods and small shifts in power relations can have transformative developmental benefits for future generations.

Resilience discourse is increasingly permeating the development cooperation landscape, including bilateral donors, UN agencies and the World Bank. Aid agencies are employing resilience largely as a framing concept to link multiple problems, stressors and responses ${ }^{51} 52$. A livelihood resilience approach helps expand the approach beyond such technical approaches to minimizing harm and loss by bringing issues of people’s lives, rights, justice, politics and power to the fore. In doing so, it demands greater attention on the societal root causes underlying differences in vulnerability and resilience.

The Rio+20 agreements have set in motion an ambitious articulation of Sustainable Development Goals (SDGs) in the light of new scientific and policy attention given to global environmental change during the last two decades. Given the timely negotiation of a new UNFCCC climate treaty to supplant the Kyoto Protocol, and development of a revised Hyogo Framework for Action on disaster risk reduction,we believe that livelihood resilience could 
become a constructive 'boundary object' that can help to merge these processes and implementation around a common objective: Anti-poverty climate and development policy.

1 Adger, W. N. et al. Resilience implications of policy responses to climate change. WIREs Clim. Change 2, 757-766 (2011).

2 Bahadur, A., Ibrahim, M. \& Tanner, T.M. Characterising Resilience: Unpacking the concept for tackling climate change and development. Climate and Development 5, 55-65 (2013).

3 Holling, C.S. in Engineering within Ecological Constraints (ed Schulze P.C.) Ch. 2 (National Academy Press, 1996).

4 Folke, C. Resilience: The emergence of a perspective for social-ecological systems analyses. Glob. Environmental Change 16, 253-267 (2006).

5 Brand, F.S. \& Jax, K. Focusing the meaning(s) of resilience: Resilience as a descriptive concept and a boundary object. Ecology and Society 12, 23 (2007).

6 Tanner, T.M \& Horn-Phathanothai, L. Climate change and development. (Routledge, 2014)

7 O’Brien, K.L. \& Wolf, J. A values-based approach to vulnerability and adaptation to climate change, WIREs Clim. Change 1, 232-242 (2010).

8 Leach, M. (ed) Reframing Resilience: a Symposium Report, (STEPS Centre, 2008).

9 Cote, M. \& Nightingale, A. Resilience thinking meets social theory: Situating social change in socio-ecological systems (SES) research. Prog. Hum. Geogr. 36, 475-489 (2012).

${ }^{10}$ Tanner, T.M. \& Allouche, J. Towards a new political economy of climate change, IDS Bulletin 43, 1-14 (2011).

${ }^{11}$ Dow, K. et al. Limits to Adaptation. Nature Climate Change 3, 305-307 (2013).

${ }^{12}$ Beymer-Farris, B.A., Bassett, T.J. \& Bryceson, I. in Resilience in the Cultural Landscape (eds Plieninger T and Bieling C) 283-299 (Cambridge University Press, 2012).

${ }^{13}$ Béné , C., Wood, R., Newsham, A. \& Davies, M. Resilience: New Utopia or New Tyranny. Working Paper 405 (IDS, 2012).

${ }^{14}$ Wrathall, D. et al. Migration and climate rigidity traps: Socio-ecological possibilism and resource politics in Honduras and Peru, Annals of the Association of American Geographers 104, 292-304 (2014).

${ }^{15}$ Cote, M. \& Nightingale, A. Resilience thinking meets social theory: Situating social change in socio-ecological systems (SES) research. Prog. Hum. Geogr. 36, 475-489 (2012).

${ }^{16}$ Ribot, J.C. in Social Dimensions of Climate Change: Equity and Vulnerability in a Warming World. (eds Mearns, R. and Norton, A.) 47-74 (The World Bank, 2011).

${ }^{17}$ Miller, F. et al. Resilience and Vulnerability: Complementary or Conflicting Concepts? Ecology and Society, 15, 11 (2010).

${ }^{18}$ Cannon, T. \& Muller-Mahn, D. Vulnerability, resilience and development discourses in context of climate change, Natural Hazards 55, 621-635 (2010).

${ }^{19}$ O’Brien, K. Responding to environmental change: A new age for human geography? Prog. Hum. Geogr. 35, 542-549 (2011). 
${ }^{20}$ Brown, K. Global environmental change I - A social turn for resilience? Prog, Hum. Geogr. 38, 107-117 (2014).

${ }^{21}$ Hayward, B. Rethinking resilience: reflections on the Earthquakes in Christchurch, New Zealand, 2010 and 2011. Ecology and Society 18, 37 (2013).

${ }^{22}$ Weichselgartner, J. \& Kelman, I. Geographies of resilience: Challenges and opportunities of a descriptive concept. Prog. Hum. Geog. (2014). Doi: 10.1177/0309132513518834.

${ }^{23}$ Marschke, M. J., \& Berkes, F. Exploring strategies that build livelihood resilience: a case from Cambodia. Ecology and Society. 11, 42 (2005).

${ }^{24}$ Speranza, C.I., Wiesmann, U. \& Rist, S. An indicator framework for assessing livelihood resilience in the context of social-ecological dynamics. Global Environmental Change 28, 109-119 (2014).

${ }^{25}$ Chambers, R. \& Conway, G. R. Sustainable rural livelihoods: Practical concepts for the 21st century. (Institute of Development Studies, 1991).

${ }^{26}$ Ashley, C. \& Carney, D. Sustainable livelihoods: Lessons from early experience (DFID, 1999).

${ }^{27}$ Ellis, F. Household strategies and rural livelihood diversification. Journal of Development Studies, 35, 1-38 (1998).

${ }^{28}$ Weichselgartner \& Kelman (Ibid. p14)

${ }^{29}$ Davidson, D.J. We Still Have a Long Way to Go, and a Short Time to Get There: A Response to Fikret Berkes and Helen Ross. Society \& Natural Resources 26, 21-24 (2013).

${ }^{30}$ Westley, F. R. et al. A theory of transformative agency in linked social-ecological systems. Ecology and Society 18, 27 (2013).

${ }^{31}$ Aldrich, D. Building Resilience: Social Capital in Post-Disaster Recovery (University of Chicago Press, 2012).

${ }^{32}$ Palmer, P.I. \& Smith, M.J. Model human adaptation to climate change. Nature 512, 365-6 (2014).

${ }^{33}$ Sen, A. Elements of a Theory of Human Rights. Philosophy and Public Affairs 32, 315-356 (2004).

${ }^{34}$ Bronen, R. in Humanitarian Crises and Migration (eds Martin, S., Weerasinghe, S. and Taylor, A) (Routledge, 2014).

${ }^{35}$ Molyneux, M.D. and Lazar, S. Doing the Rights Thing: Rights-Based Development and Latin American NGOs (ITDG, 2003).

${ }^{36}$ Satterthwaite, D. \& Mitlin, D. Reducing Urban Poverty in the Global South (Routledge, 2014).

${ }^{37}$ Pelling, M. Adaptation to climate change: from resilience to transformation (Routledge, 2010).

${ }^{38}$ Brown, K. \& Westaway, E. Agency, Capacity, and Resilience to Environmental Change: Lessons from Human Development, Well-Being, and Disasters. Annual Review of Environment and Resources 36, 321-342 (2011).

${ }^{39}$ Welsh, M. Resilience and responsibility: governing uncertainty in a complex world. Geog. Journal 180, 15-26 (2014) ${ }^{40}$ Lewis, D. Non-Governmental Organizations, Management and Development. (Routledge, 2014).

${ }^{41}$ Bronen (Ibid)

42 Smith, M.S., Horrocks, L., Harvey, A. \& Hamilton, C. Rethinking adaptation for a $4^{\circ} \mathrm{C}$ world. Phil. Trans. R. Soc. A 369, 196-216 (2011).

43 O’Brien, K. Global environmental change II: From adaptation to deliberate transformation. Prog. Hum. Geogr. 36, 667676 (2012). 
${ }^{44}$ Kates, R. W., Travis, W. R., \& Wilbanks, T. J. Transformational adaptation when incremental adaptations to climate change are insufficient. PNAS. 109, 7156-7161 (2012).

45 Park, S.E. et al. Informing adaptation responses to climate change through theories of transformation. Global Environmental Change 22, 115-126 (2012).

46 Leach, M. (ed) Reframing Resilience: a Symposium Report, (STEPS Centre, 2008).

47 Pelling, M. Adaptation to climate change: from resilience to transformation. (Routledge, 2010)

${ }^{48}$ Walker, B., C. S. Holling, S. R. Carpenter, and A. Kinzig. Resilience, adaptability and transformability in socialecological systems. Ecology and Society 9, 5 (2004).

${ }^{49}$ Lebel, L. et al. Governance and the capacity to manage resilience in regional social-ecological systems. Ecology and Society 11, 19 (2006).

50 ISSC/UNESCO. World Social Science Report 2013: Changing Global Environments (OECD Publishing and UNESCO Publishing, 2013).

51 Weichselgartner \& Kelman (Ibid.)

52 UNDP. Human Development Report 2014: Vulnerability and Resilience. (United Nations Development Programme, 2014). 